\title{
Institutions and Disadvantaged: Intervention or Oppression? Theatre of the Oppressed at the Universities
}

\author{
Dana Moree, Selma Benyovszky \\ Charles University, Faculty of Humanities
}

\begin{abstract}
Theatre of the oppressed is a method invented for working with disadvantaged groups of population. However, it is more and more often used also at the universities which represent more elite part of the society. This contrast leads us back to the question of Augusto Boal - the inventor of the method and to the core question of the method - where are the people? While universities prepare students also for working with marginalized groups and we know that marginalized population is underrepresented there, we would like to address the same question as Augusto Boal. The aim of the article is two folded: we discuss possibilities and limits of TO for working at the universities. And we share one concrete example of the group which topic was sexual abuse at school environment.
\end{abstract}

Keywords: theatre of the oppressed, power, universities, teaching methods, sexual abuse

Theatre of the oppressed (TO) was invented by Augusto Boal as a method which served to those, who are voiceless. The audience during performances were those who experience the same situations or troubles (like e.g. peasants in poor neighborhoods in Brasil perform for peasants) (Boal, 2001). However, this method became much more accessible last thirty years and applied in many environments including universities (Christensen, 2014; Desai, 2017; Giesler, 2017; Stahl, 2018).

The aim of the article is to discuss the implementation of TO at the university and share an example of one theatre performance as a source of impulses for this discussion. The reason is that implementation of the method targeted originally at disadvantaged population is very often used in totally different contexts. The question is what are its possibilities and limits at the same time.

\section{Introduction to Theatre of the oppressed}

First of all, let us have a closer look at the roots - how the method was invented, what were the impulses for its creation. Boal (2001) was a theatre director at the beginning of his career and at the same time he faced a deep political and societal crisis in his country. Given the fact that the audience were mostly representatives of middle and upper class, his driving force was a feeling that he legitimizes power of disadvantaged by means of the theatre if he performs about troubles of those who are powerless. His basic question was - where are the people? Many attempts 
10 to solve this dilemma resulted in the theatrical form, which we call theatre of the oppressed today (Boal, 2001).

Department of Civil Society at Charles University in Prague started to implement this method in 2013. Students of the department are prepared for working in civil society and NGOs but at the same time they work in the field of Corporate Social Responsibility or in managerial posts at government institutions. In many of these contexts they should be prepared for working with disadvantaged groups of population or at least with those whose voice is weaker. However, due to the fact that students of the universities do not have much experience with disadvantaged groups of population. It brings their teachers into the same question as Augusto Boal - where are the people?

When we take a critical perspective, we have to ask the question if universities are the place where education should contribute to solving social problems in society (Smeyers \& Depaepe, 2008). Even if we take a position, which it is not the case, we face two issues: theatre of the oppressed is more and more often used as a teaching method at the universities although it is a method invented for disadvantaged parts of population and graduates of universities will work with those, whom they have never met before - thus - with disadvantaged ones.

When we take broader perspective, we can also have a look at the latest developments at universities and high schools in the Czech Republic. They are facing a new situation as a result of the reform articulated in Act 137/2016. One of the results of this reform is that the country's universities are to be divided into practically oriented and academically oriented institutions. Academically oriented universities increasingly tend to be reduced to producers of highly achieving academic publications, where international competition is seen as more and more important.

When we look at the demographic composition of the university environment, we know that universities worldwide very often reproduce power differences in societies (Mann, 2008) and that students from minority or disadvantaged social and ethnic backgrounds are still underrepresented (Ghofa, 2017; Mann, 2008). Moreover, students are perceived as passive absorbers of curricula, created in a difficult system of accreditations (Mann, 2008). They are not given many possibilities to influence or change the environment they study in or the ways they are taught.

When students cannot influence the curricula, the ways they are taught or the composition of the student population, tailored teaching methods might offer an opportunity to integrate an aspect of reflection, training in the ability to act differently, and support for social skills at university.

We know that learning environment and teaching strategies are closely linked to social skills students can learn. Scholars like Dewey, 1903, 1916, 1938; Freire, 1974; Oser \& Veugelers, and others have presented valuable evidence about the necessity of creating a nurturing learning environment and how that can be done. The question is what is the position of TO in this debate. And how can this method contribute to the issue of difficult relation between education and broader societal context (Simons \& Masschelein, 2008). 
We begin by introducing the theatre of the oppressed and analyzing its potential

for implementation at universities and its limitations. We then present the results of the theatre of the oppressed group work, in which students of Charles University (Prague), students from grammar school in Prague and clients of a youth club in Prague participated. Sexual abuse appeared to be a hot topic in the group and so a theatre performance called "Deka [Blanket]" grew out of their collaboration. We conclude the paper with a discussion of this experience and what it shows us about the implementation of the theatre of the oppressed method in a university environment.

\subsection{Theatre of the oppressed at universities}

Theatre of the oppressed is a method that has previously been explained in many texts (Conrad, 2004; Christensen, 2014; Desai, 2017; Giesler, 2017; Saeed, 2015; Stahl, 2018). We will introduce it only briefly here. When we take a perspective of its practical implementation, we can mention that it works as follows. A group of people who have experienced injustice, difficulties or oppression and express the willingness to work on these topics works together using a wide range of techniques that promote their ability to recall their experiences, express them through their bodies and embody them into new story, which is "translated" into theatrical language. The techniques used have been described by Augusto Boal and his followers (Boal, 1979, 1992).

The resulting theatrical work is performed in front of an audience - ideally an audience that may have had a similar experience. The aim of the performance is to encourage social change. The audience actively looks for ways to address the situation depicted. This stage in the process is known as forum theatre.

The method was originally developed for work with disadvantaged groups in environments like slums, prisons, ghettos, etc. (Boal 1979, 1992). However, when Augusto Boal was forced to emigrate, he adapted this methodology for work with less disadvantaged people, who have not experienced external oppression (like being beaten on the street), but have experienced internal oppression from the voices in their society, family, institutions. In other words, he adapted the method to help people cope with any kind of social pressure. This method was called "Rainbow of desire" (Boal, 1995). Boals looking for people became inevitable part of developing theatrical methods and at the same time, target groups with whom he worked influenced its further development. We can see that the method and its target groups were in constant dialogue.

Being aware of this fact, we adopted several strategies during the last years, which affected especially the way, how we composed the groups working with the theatre of the oppressed method at the university:

1) We started to work with students of the university in a framework of a voluntary part of their studies. Theatre of the oppressed was offered as a voluntary course only to students. 
12 2) Then the stage of "looking for people" started - we started to look for a way how to achieve contact between students and other target groups outside the university. One of the students brought a strong impulse - she wrote theses about identity and citizenship of representatives of young Roma. She was conducting interviews with them and they expressed willingness to try to do something together. The first contact arose. Based on this we invited students and young Roma to make a theatre performance together.

3) Mixed strategy started to be adopted. Sometimes there is an impulse from a concrete target group of disadvantaged population willing to create a theatre performance (like homeless people, NGO working with Vietnamese population etc.) and students do not participate; sometimes we try to react on societal hot topics like during refugee crisis, when we used open call among students and NGOs working together and sometimes we offer students possibility to participate in a project, which is conducted together with other institutions or NGOs.

The fact that there are students working together with people outside university under the leadership of university teachers can be discussed from many perspectives. It could be approach from the perspective of teacher-student relationship and the way how the dynamics of this relation is formulated (Fendler, 2001), from the perspective of deliberative democracy and the whole discussion about possibilities of equality in such a mixed group (Mouffe, 2000) and many others. We would like to offer a perspective of identity building, which we identified as the most important during working with mixed groups and seems to be important also for the way, how the group makes a choice for the topic of the performance (Moree, Vavrova, $\&$ Felcmanova, 2017).

When the group is composed of people who are visibly different or whose life experience differs significantly, there might be a strong "we" and "they" dynamics. Students can be perceived as those, who did not experience "real" oppression or they have a feeling that their oppression is not "good enough". But we know from the literature that it necessarily does not need to be as simple. We know e.g. that a significant proportion of students experience some kind of sexual harassment (Christensen, 2014). At the same time students are less free in the university space, because they experience university environment in many ways. There are students, who experienced strictly hierarchical environment, which does not give them much opportunities for a participation. Other students experience safe space for exploring, developing own thoughts and expressing them.

Participants outside the university often bring very clear issue with a strong experience. But at the same time they do not have any previous experience with the university environment, no obligations, and no credits duty in this environment.

Oppression in modern society is very often linked to power issues and equality and it usually happens not as a byproduct of homogeneous environment, but as a result of situation that people come together and are not treated equally, which is very often also a driving force for creating the story in theatre groups. E.g. when a group makes a decision to work on racism, its members experience dichotomy of 
we and they, which is crucial perspective for creating the story. The point is not the fact that part of participants experienced racism and others did not. We all know how racism works, but there is different experience in case the concrete person has different skin color and in case he or she is e.g. representative of silent majority (Moree, Vavrova, \& Felcmanova, 2017).

But at the same time the group does not experience only this aspect of "divided experiences" because they also experience its growing into a team. Otherwise they would not be able to create something together, experience strong flow of ideas, safe space for creative work (Dewey, 1938). These issues happen only in a safe environment (Csikszentmihalyi, 1991; 2013). It means that something must happen. Dovidio et al. (2007) suggest that one of possibilities how to overcome dynamics of division into we-they is so called principle of dual identities. If people in mixed environment experience that they can keep their own identity and at the same time create a new common identity (like theatre group) it gives an opportunity to work together and experience group identity in a new way.

This sensitive issue demands that we ask ourselves several questions with every new theatre group: who is going to participate, how is the participation defined, and what is the result of implementing the theatre of the oppressed? We can look at these questions step by step.

Who is going to participate? In many of the studies that have been published, the participants of the theatre of the oppressed groups were all university students (Desai, 2017; Stahl, 2018). While this certainly has many advantages - the students know each other and it is easier to create a safe space in a well-known environment - it does not overcome the problem of the underrepresentation of disadvantaged groups. What might be reasons to stay in a safe space of students' population and what might be the reasons to make decisions for mixed group composition?

How is the participation defined? If theatre of the oppressed is offered as an optional course, students choose to participate, but must then fulfill the requirements of the course. This can become difficult if the topic is too sensitive (Stahl, 2018) and working on such sensitive issues may harm the students.

What is the result of implementing the theatre of the oppressed? The original method leads to a public performance known as forum theatre, at which the audience can react, try to change the destiny of the main character, and provoke social change. Should such a performance be an obligatory part of theatre of the oppressed when it is implemented at universities?

For further discussion, we made a decision to analyze experience of a group composed originally from students of Charles University, one grammar school and clients of NGO People in Need. Their shared topic was sexual harassment, which they all experienced to some extent. 


\section{Theatre of the oppressed and research}

\subsection{Theatre of the oppressed as research method}

Theatre of the oppressed was not originally created as a research method. It is a way of working, whose aim is social change, transformation of oppressed individuals' experiences and empowerment (Boal, 1979). However, this method is very intensive and the work generates deep insights into the problem that the group is attempting to solve. It is therefore logical that it attracts researchers wishing to make use of these data. Most often, theatre of the oppressed is linked to action research (Lewin, 1946). The group process is reflected and the results and reflections by the participants are shared (Wrentschur, 2008; Call-Cummings \& James, 2015).

We too applied this research strategy for three years. However, because we were working with groups composed of people from different social, ethnical and generational backgrounds, it turned out to be insufficient. Very often we encountered situations in which tiny reinterpretations of well-known theoretical concepts like integration, exclusion, etc. happened as a side product of the group process. And that view of theory, created by the group, was then tested and redefined during their interaction with an audience. We were unable to capture these subtle effects through action research. We needed something more similar to the research analyzing nuanced reinterpretations like those by Dvora Yanov and van der Hart (2013). This led us to look for new research approaches that could be usefully applied to this kind of group process. We began to use a mixed methodology divided into two stages:

Stage 1 - preparing the theatre performance. This stage was perceived as a process of formulating a research question, where the group of participants formulates the question itself. We used ethnography based on field notes during this stage (Moree, Vavrova, \& Felcmanova, 2017).

Stage 2 - performing with an audience. This stage was perceived as a process of collecting data that could answer the research question formulated in stage 1 . We recorded the performances and code the data created by the audience, combined with field notes.

To illustrate this way of working with the theatre of the oppressed at university, we now share the data and processes of one case, in which a group of students worked on the topic of sexual harassment at school.

\subsection{Sexual harassment in the theatre of the oppressed - formulating the research question}

In spring 2016 a group composed of Charles University students, grammar school students, youth connected with one NGO and several other young people connected with other NGOs in Prague came together. It is also important to mention that this group worked before the campaign "Me Too" started. This co-operation was initiated by co-operation between NGO and Charles University in one project. The group 
was formed, there were decisions made about place where the group would work together and time distribution (they made a decision to work during the weekends in blocks of 5-7 hours). The group process started as part of a course offered in the summer term and university students were offered to be connected with participants from other institutions. These were volunteers participating in the youth clubs of two NGOs in Prague - Člověk v tísni [People in Need] and InBáze. We list the basic characteristics of the participants with their performance names below:

Jáchym - 17-year-old male grammar school student

Anežka - 22-year-old female university student

Policeman and school psychologist - 17-year-old male grammar school student

School principal - 22-year-old female university student with migration background Psychologist at the police station - 19-year-old female grammar school student with minority background

Policeman - 24-year-old female university student

\section{Schoolmates:}

Two female university students with migration backgrounds

One male university student with homosexual orientation

Three female university students

The group started out with 21 participants, but reduced to the above participants after the first part of the group process because the other group members did not want to perform. The decision not to perform was usually due to time pressures.

The group process started as always using Boal's techniques (Boal, 1979, 1992). The first topics of oppression that were raised within the group were: pressure to be perfect, pressure from parents to succeed, unspecified societal expectations of young people, pressure to be heterosexual, pressure to submit to the dominant discourse and its ideas of what is normal.

The oppression mirrored in the theatre of the oppressed techniques (e.g. image theatre) consisted of exclusion from the group based on the above experiences and misunderstandings in the family. Due to the fact that the group consisted with people from different background and life experience, at first sight it seemed that they would not find a common topic. After two months of intensive work the group was not able to find a topic with which to create a story, but they did not want to stop the group process. It was clear that there was another topic hiding in the background of the group's work that had not yet been accessed. Eventually, this intuition was openly mentioned in the group, which resulted in one member of the group pronouncing the topic of sexual abuse during a school trip. In real life he reacted on the situation, contacted police and school leadership. The result was that the police announced their decision to defer further investigation due to a lack of evidence under the argument that if the victim is strong enough to go to police, then he is also psychically healthy enough to express his will not to be abused in real situation. The rest of the group appeared to have a strong connection with the story, because 
16 they had experiences of the same sort, albeit not so strong (one girl was e.g. filmed during changing clothes together with other girls from volleyball club by the trainer, one girl was beaten by a teacher at school ...).

After this sharing of stories, the group went through a careful decision making process to establish whether they felt ready to work on the topic publically. In general the participants were very positive. They felt powerless in real life and they wanted to make use of their experience for the wider public and for those who might experience similar difficulties. And so the performance started to take shape.

\subsection{Deka [blanket] performance - looking for answers of the research questions}

The performance opened with policemen reading a quotation from the real report taken when 17-year old Jáchym came to the police station. He announced that he had participated in a school trip outside Prague and had repeatedly been touched on intimate parts of his body by his physical education (P.E.) teacher during the night.

The schoolmates then came onto the stage and a lesson began. Jáchym came in late and the teacher was angry with him about his behavior in recent weeks. After the class, Anežka - Jáchym's good friend - came over to ask him what was wrong, and Jáchym tried to explain what had happened to him. Anežka helped to communicate his troubles to the other schoolmates and it began to be clear that Jáchym had not been the P.E. teacher's only victim, and that other pupils had been having the same experience. Jáchym made the decision to fight against this, to try to ensure that it would not happen again.

First of all, he went to see the school psychologist. The psychologist was supportive, but explained that he could not do anything and suggested that Jáchym should talk to the school principal. The principal did not trust Jáchym and said that she could not do anything because this was an issue for the police to deal with. But Jáchym did not want to take it to the police, because he was ashamed of what had happened to him and did not want any public attention. He asked the principal whether she could at least be excused from physical education lessons, where he had to spend time with the teacher who had abused him, but this was denied - he was told that he could only be excused if he brought confirmation from his doctor that he could not participate in P.E. for health reasons. In the end Jáchym went to the police station, where he was treated very insensitively. At the end of the performance another quotation from the police report is read, in which the police announce their decision to defer further investigation due to a lack of evidence.

The question the group asked the audience to reflect on was how the situation could be handled such that Jáchym would experience respectful treatment and the teacher would be punished.

The performance was performed in Švandovo theatre in Prague and the audience was of a mixed origin - friends and social network of the actors, which means friends and family members of university students, clients of NGO etc. 


\section{Results}

At the end of the performance, the audience was asked what they thought about the main character's motivation. Their answer was that he wanted to prevent the same thing from happening to anyone else. This requirement that the situation and, consequently, the trauma - should not repeat is used as a thesis for our data analysis. The aim is to analyze the process of the audience's re-building during one performance of Deka. An open coding method is used, in which five categories were crystallized: anonymity, loneliness, public secret, popularity, and institutions of power. In this part, only the scenes requested by the forum will be discussed.

\subsection{Loneliness}

The main category identified, although it is not the most important, is loneliness. At the beginning of the forum, the audience first wanted to try out the scene in which the main character Jáchym tells his schoolmates about the incident and discovers that he was not the only one abused by the P.E. teacher. When intervening in this scene, one audience member tried to persuade a boy who had had a similar experience with the same teacher to talk, but he did not want to be involved. The main motivation of this intervention was to find allies in order to reduce Jáchym's loneliness.

Searching for allies occurs in other scenes, too, where the endeavour to overcome the loneliness remains the main topic. Loneliness seems to be logically connected with the subject of the story, the main focus of which is the hopeless situation Jáchym finds himself in when he attempts to accuse the P.E. teacher. Simply said, from a legal point of view this is just one person's word against another's word.

During the discussion after this scene, the audience member, who had tried to convince the other abused schoolmate Jarda to go with her to the school psychologist, said: "I felt like I was not alone and that it would give me courage [to solve it]."

After several other unsuccessful attempts to resolve the situation by the forum, the participants tried to evaluate the strategies that they had tested. They concluded that when the others do not want to open up and go public with their story, Jáchym's loneliness grows deeper. One audience member, for example, admitted in response to her effort to find allies: "It is problematic because [without any ally] one feels even more alone. I expected that he [Jarda - the other harassed schoolmate] would help me."

The audience regarded loneliness as the primary issue at play, but paradoxically, trying to find allies put the main character in the role of the victim ${ }^{1}$ and this creates a dichotomy of Jáchym versus others. This dichotomy is reinforced by the attempt

1 The term victim was understood by the audience not in the legal sense but as a psychological construct with all connotations associated with it, such as feelings of powerlessness (in the sense of power-less) and loneliness. 
18 to help the protagonist and, on the contrary, weakened by the willingness to participate in solving the situation.

\subsection{Public secret and anonymity}

During the performance, two closely related categories - public secret and anonymity - emerged. After its unsuccessful attempt to find more witnesses, the forum tried to change its strategy. By reworking several scenes, the forum discovered that the students and staff at the school knew about the P.E. teacher's inappropriate behaviour but that no-one wanted to confront him directly.

While the category of anonymity emerged throughout the discussion when the forum was debating which scenes to choose, the category of public secret was reflected primarily during the scenes themselves. Both categories were reflected the most in the requested scenes with the principal and schoolmates. In the scene when the students speak to the principal, it was obvious that the principal herself was acquainted with the behavior of the P.E. teacher, but it seemed like it was too hard for her to take a strong stand. After this, the forum requested another scene with the principal and the P.E. teacher, in which it was confirmed that the P.E. teacher's tendencies were commonly known.

The category of anonymity emerged gradually during the evening. The audience first found out that Jáchym's friend Jarda, who was also abused by the P.E. teacher, refuses to admit it publicly. The forum tried to encourage him to help Jáchym, using various tactics: first, trying to persuade him to be an ally (see above on the category of loneliness), then by trying to convince him that he will help himself by coming out with his story, and finally by trying to awaken his empathy. None of the tactics worked, and gradually, the forum adopted the requirement of anonymity, which was most evident in the scenes with the principal and school psychologist where the actors in Jáchym's role persistently refused to make their identity public and refused to go to the police as a result of this desire for anonymity. Their efforts to maintain anonymity thus increased the public-secret effect. A frame example was a scene where an audience member, as Jáchym, went to the school psychologist, told him that he and another two male schoolmates were harassed by the P.E. teacher, and ask him to convince the principal to dismiss the teacher. The school psychologist tried to explain that he could not do anything and that the only way is to lose their anonymity. The students refused this solution at first and it was only once the other scenes had shown that the situation could not be solved while they remained anonymous that the forum decided it was best to come out with the truth and confront the principal directly.

\subsection{Popularity}

Power appears to be the most important aspect both in the category popularity and in institutions of power. The popularity category demonstrates that mere popularity can create and construct a major power. The teacher's popularity se- 
ems to represent a significant obstacle in the audience's search for a solution. It

blocks their path whenever they try to find allies both among the authorities (i.e. the principal, the psychologist) and among the students. Moreover, the forum does not question or even attempt to deconstruct the teacher's popularity, but takes it as given.

When an audience member, acting as Jáchym, wants the other abused schoolmate Jarda to talk about what happened to him with the P.E. teacher, Jarda refuses and argues that he cannot do it because the teacher is nice and popular. In another scene, when an audience member acting as Jáchym wants the principal to fire the P.E. teacher, the principal argues that he has been teaching for 30 years and everybody likes him. The popularity of the teacher is used as a confirmation of his credibility. Only in one scene was popularity used with the reverse effect: in a conversation with the P.E. teacher, the principal expressed doubts that someone would make up a story of harassment involving the most popular teacher.

\subsection{Institutions of power}

Institutions of power include the school and its authorities as well as state institutions, i.e. institutions that have a strong influence on people's lives. Throughout the process the audience expressed a substantial lack of trust in these institutions. For example, in a requested scene with the school psychologist, an audience member acting as Jáchym refused to go to the police. After this, the forum decided to try to convince the school authorities to fire the P.E. teacher. When they failed, they concluded that it was necessary to go to someone "higher", but still not to the police. Contrarily, the forum consistently tried to bypass the police force and preferred to focus on human rights institutions that were considered to be separate from the state and thus more affable. Even when the joker repeated it became clear that no-one but the police could do anything to help, the forum refused to try a scene with the police. Then, joker № 2 intervened:

I just have a question ... I am asking myself ... It is clear that in accordance with the law, the police play a key role in this event but it is a bugaboo... So I just want to know what makes us feel like it is so hard to go to the police? Who gives them their power and how is it possible that they do not protect 16-year-olds from this sort of situation?

Forum participant reacted:

There is a Labor Code for such cases. And just because someone says something somewhere, even if it is true, it is not enough to fire someone. If I want to dismiss someone, he must be punished first. Who will punish him? The police will punish him. So it is necessary to go to the police, this is obvious in this story. It is only when the guilt is proved that the person can be dismissed. If one doesn't go to the police and [the principal] just fires the person, nothing will be solved. The man will go somewhere else... 
The joker № 2 intervened:

And that is exactly the thing! If the director had fired him, just like that, so what next? The man will go to the next school, he will not have any criminal record or anything. I mean, I understand that it is kind of annoying to you that we look like we know how these people would act. We probably do not know if the teacher would say again whether he was change his shoes or not, which, by the way, was a real thing that happened in that situation, but it doesn't matter. The director tells him "I can't do anything about it".

The discussion that followed this question soon turned into a debate about what the principal should have done and what power she has. And even after several motions from the joker to try a scene with the police, nobody responded to that suggestion.

This performance has been performed six times during the past two years. The audiences have all refused to question the practices of the police and other institutions that hold formal power in society. The main argument was that common experiences with police are so bad and insensitive that it is almost impossible to go there with such as intimate issue as sexual abuse.

\section{Discussion and conclusion}

In this article, we wanted to discuss limits and possibilities of theatre of the oppressed as method which is more and more often implemented at the universities. We also wanted to provide a concrete example of one development of a performance, in which university students co-operated with young people from other institutions concretely with clients of youth club in one NGO from Prague. In our conclusions we will begin by reflecting on that practical example, with the performance Deka.

Although the audience stressed the category of loneliness the most during the performance, our data analysis shows that the most important category for them was institutions of power. The answer to the research question formulated by the group is, thus, to bypass the police in finding solutions.

The audience perceived the police - as a strong state authority with the potential to use violence - as a core element of the ossified system (in which the school is included) in which rules and bureaucracy are remote from or superior to people. Although in liberal democracy it is clear that the police should be the first place to go in such situations, everyone - including the principal and school psychologist - tried to avoid involving them. The forum did not want to try a scene with the police to change the main character's destiny. Instead, they focused on the character's loneliness, and put the element of power and its legitimacy aside. The legitimacy of the police - which is not unchangeable - was thus uncritically accepted and ignored by the audience. In spite of the jokers' efforts to return the audience to the issues of 
power and the legitimacy of the police, the performance ended with the conclusion that the perpetrator could only be condemned morally.

The development of the performance was influenced by the participants' real life experiences of traumatic situations. Theatre of the oppressed seems to be a powerful tool for bringing students into a reflective learning process and thinking about change. The power of using theatre of the oppressed at universities lies in the fact that it enables the students themselves to provoke changes in interaction with their audience. However, we recognise also its limits and challenges:

The single fact that we read and write academic articles makes all of us representatives of elite - middle class, those, who are powerful. However, theatre of the oppressed was created as a method, which should serve to diminish inequality in the society. The first aspect is thus an ethical one. In case we do not implement the method in accord with its original aim, we might also represent those, who reproduce inequality in the society and then we might use the method for the opposite purposes. This aspect worth a separate article, but at the same time it is an important background for further discussion.

We can conclude that there are reasons to use TO at the universities but at the same time there are reasons to look for the way how it is implemented. Then we perceive several important aspects:

1) The probability that students explore very sensitive experiences during the process is quite high. Power relations should be solved with the teacher of the course so that the students' trauma is not reproduced. This requires investing time and energy into creating a safe space and trust in the group and include collective decision making in all stages of the process. In this aspect when a course is built on the TO, there should be a special and more sensitive way how to use it and how to teach.

2) There are reasons to open university and work by means of TO with mixed groups. In such a case careful working on identity of the whole group is crucial to avoid feelings of being less important than the others. Boal (1995) suggests that there are much more aspects of oppression in the society then clear external oppression. And he was very open for adapting the method to all kinds of oppressions. But when we implement TO at the university, we should be careful about the way how every single group and individual is treated. Dual identity of actors provoking societal debate about an issue, which the group identifies as important, might be possible solution.

3) All participants should experience the opportunity of taking part in decision-making during the whole process of theatre of the oppressed. Which means that the whole process might be risky from the perspective of e.g. project outcomes. If the group makes a decision not to perform, institution should be prepared to accept the decision and not to make the group to finish from any formal or practical reasons.

In other words, in our view theatre of the oppressed is a powerful tool and it is possible to implement it also at university level. However, its implementa- 
22 tion requires the relevant course to be organized in a rather special way, with a focus on treating participants with sensitivity and enabling their participation in decision-making processes. Theatre of the oppressed very often reopens traumatic experiences and when students and other participants bring these to the process, the courses should be able to offer a corrective experience in contrast with the original traumatic situation.

\section{Acknowledgement}

This publication was supported by the Ministry of Education, Youth and Sports - Institutional Support for Long-Term Development of Research Organisations - Charles University, Faculty of Humanities (2019).

\section{References}

Boal, A. (1979). The theatre of the oppressed. New York: Urizen Books.

Boal, A. (1992). Games for actors and non-actors. New York: Routledge.

Boal, A. (1995). The rainbow of desire. London: Routledge.

Boal, A. (2001). Hamlet and the baker's son. My life in theatre and politics. London: Routledge.

Call-Cummings, M., \& James, Ch. (2015). Empowerment for whom? Empowerment for what? Lessons from a participatory action research project. Networks: An Online Journal for Teacher Research, 17(2), 1-9.

Christensen, M. C. (2014). Engaging theatre for social change to address sexual violence on a college campus: A qualitative investigation. British Journal of Social Work, 44, 1454-1471.

Conrad, D. (2004). Exploring risky youth experiences: popular theatre as a participatory, performative research method. International Journal od Qualitative Methods, 12-22. doi: $10.1177 / 160940690400300102$

Csikszentmihalyi, M. (1991). Flow. New York: Harper Perennial.

Csikszentmihalyi, M. (2013). Creativity. New York: Harper Perennial.

Desai, S. R. (2017). Utilizing theatre of the oppressed within teacher education to create emancipatory researchers. Multicultural Perspectives, 19(4), 229-233.

Dewey, J. (1903). Democracy and education. The Elementary School Teacher, 4(4), 193-204.

Dewey, J. (1916). Democracy and education. New York: Barnes \& Noble.

Dewey, J. (1938). Experience and education. New York: Kappa Delta Pi.

Fendler, L. (2001). Educating flexible souls: The construction of subjectivity through developmentality and interaction. In K. Hultqvist \& G. Dahlberg (Eds.), Technologies of the self: A seminar with Michael Foucault (pp. 119-142). London: Tavistock Publication.

Freire, P. (1974). Education: the practice of freedom. Santiago (Chile): Institute for Agricultural Reform.

Giesler, M. A. (2017). Teaching note - theatre of the oppressed and social work education: radicalizing the practice classroom. Journal of Social Work Education, 53(2), 347-353.

Gkofa, P. (2017). Promoting social justice and enhancing educational success: suggestions from twenty educationally successful Roma in Greece. Urban Review, 49, 498-509.

Lewin, K. (1946). Action research and minority problems. Journal of Social Issues, 2(4), 34-46.

Mann, S. (2008). Study, power and the university: The institution and its effects on learning. New York: McGraw-Hill Education. 
Moree, D., Vavrova, T., \& Felcmanova, A. (2017). Blue or red, why do categories attract? Urban Review, 49, 498-509.

Mouffe, C. (2000). Deliberative democracy or agonistic pluralism. Reihe Politikwissenschaft I Political Science Series [Institut für Höhere Studien, Wien], 72, 2-30.

Oser, F. K., \& Veugelers, W. (Eds). (2009). Getting involved; global citizenship development and sources of moral values. Rotterdam: Sense Publisher.

Saeed, H. (2015). Empowering unheard voices through theatre of the oppressed: reflections on the legislative theatre project for women in Afghanistan - notes from the field. Journal of Human Rights Practice, 7(2), 299-326.

Simons, M. \& Masschelein, J. (2008). The governmentalization of learning and the assemblage of a learning apparatus. Educational Theory, 4, 391-415.

Smeyers, P., \& Depaepe, M. (Eds.). (2008). Educational research: the educationalization of social problems. Wiesbaden: Springer.

Stahl, S. (2018). Acting out to call in: practicing theatre of the oppressed with high school students. The Educational Forum, 82, 369-373.

Yanov, D., \& van der Hart, M. (2013). People out of place: allochthony and autochthony in the Netherlands' identity discourse - metaphors and categories in action. Journal of International Relations and Development, 16, 227-261.

Wrentschur, M. (2008). Forum theatre as a participatory tool for social research and development: A reflection on "Nobody is perfect" - a project with homeless people. In P. Cox, T. Geisen, \& R. Green (Eds.), Qualitative research and social change (pp. 94-112). United Kingdom: Palgrave Macmillan.

Mgr. Dana Moree, Dr. Charles University, Faculty of Humanities U Kř́že 8, 15800 Praha 5,Czechia dana.moree@fhs.cuni.cz

Mgr. Selma Benyovszky Charles University, Faculty of Humanities U Kř́že 8, 15800 Praha 5,Czechia selma.benyovszky@fhs.cuni.cz 